\title{
Effect on Marine Life by Noise of Offshore Wind Farm
}

\author{
S.JIANG ${ }^{1} \&$ J.P.HOU ${ }^{1}$ \\ ${ }^{1}$ Third Institute of Oceangraphy,SOA,Xiamen,Fujian,China
}

KEYWORD: Offshore wind farm; Marine Life; Underwater noise

ABSTRACT: Offshore wind farm monitoring results show that: Spectrum fan running in the underwater noise level substantially are more similar to the overall strength significantly smaller with increasing frequency, in $1 \sim 20 \mathrm{kHz}$ frequency distribution of the power spectrum level $140 \mathrm{~dB} / 1 \mu \mathrm{Pa}$ to $65 \mathrm{~dB} / 1 \mu \mathrm{Pa}$, at $120 \mathrm{~Hz}$ to $1.5 \mathrm{kHz}$ with a wide spectrum of crony shape, strength increased to $10 \sim$ $20 \mathrm{~dB} / 1 \mu \mathrm{Pa}$. Studies show that the fan noise of marine fish and mammals may have some impact, but it will not cause adverse physiological reactions and hearing damage; the same time, some studies show that marine organisms can adapt well to the fan noise, does not adversely affect.

\section{INTRODUCTION}

Wind power is clean and renewable energy which has big potential and matured technology. Uder the situation of the emissions of reducing the greenhouse gas, in the new situation as climate change, it already caught wold attention and has a large-scale development and worldwide utilization. At present, China's wind power installed capacity has exceeded 20 million $\mathrm{kW}$, basically onshore wind farms. Most developed coastal areas in China are most shortage of energy, if build equipment to get offshore wind power, it is not only has a great significance for alleviating the power shortage situation but also has an effective to climate change.

Underwater noise generated by offshore wind farms will bring impact on the marine environment; it is the most urgent things like exploring the breadth and depth of its impact and making of positive and effective way to reduce the impact.

\section{GETTING THE NOISE SOURCES OF OFFSHORE WIND FARM}

Offshore wind farm which including the underwater noise during the construction and operation. The sources of underwater noise.during the construction is mainly underwater piling or which $h$ caused by construction machinery and ships. The biggest impact which caused by noise of underwater noise at operation is generated by the operation of the fan.

Propagation path of the underwater piling noise shown in Figure 1.

Fig.1 Route 1 means the reflection path of the sea surface. The noise generated by impact hammer through sea reflection then transmitted to receiving terminals. Route 2 is the direct path of underwater noise generated by the pile then directly transmitted to the receiving end; route 3 reflection path of seabed, the noise after bottom reflection then to receiver. Route 4 the compression waves and shear which generated by the impact hammer like it impact force to the seabed, the waves propagated in the sea and some energy of noise incoming water. The propagation paths are similar between pile by Vibration and impact piling.

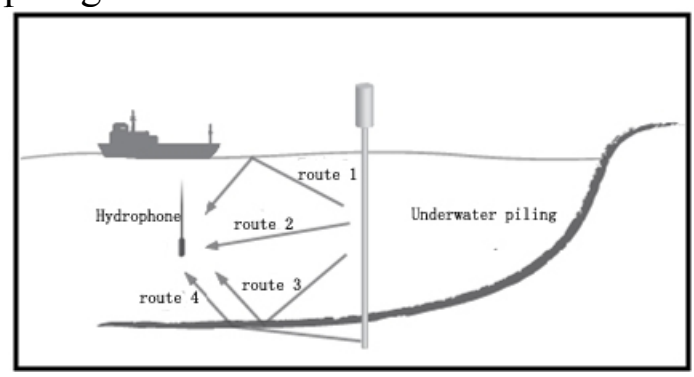

Figure 1 The propagation path of the noise which caused by impact hammer of underwater 
The underwater noise during propagation is mainly generated by the fan operation; the main way of radiated noise under water is the noise source of the fan propagation run directly from the air to sea surface then reflection to sea underwater, conduction to the water tower through the fan from the fan tower to the seabed and then radiated into the water three sound propagation paths shown in Figure 2 .

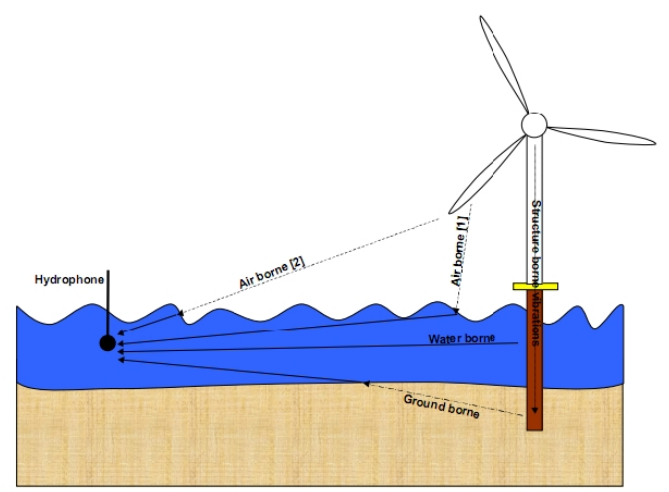

Figure2 The transmission paths for the underwater noise which caused by running fan

\section{UNDERWATER PILING NOISE}

Studies have shown that: shallow waters percussive pile (diameter of about $1 \mathrm{~m}$ ) sound source-level construction is about $194 \mathrm{~dB}$ re $1 \mathrm{uPa}, 400 \mathrm{~m}$ distance SPL 134dBreluPa; Susanna B. Blackwell (2004) study shows that: in shallow water depth of $12 \mathrm{~m}$, whales from the percussive pile construction 80m (Figure 3, Figure 4) at the measured sound pressure level not exceeding US national Marine fisheries Agency (NMFS) issued by the maximum sustainable standard sound pressure $180 \mathrm{~dB}$ re 1uPa (NMFS, 2000 ).

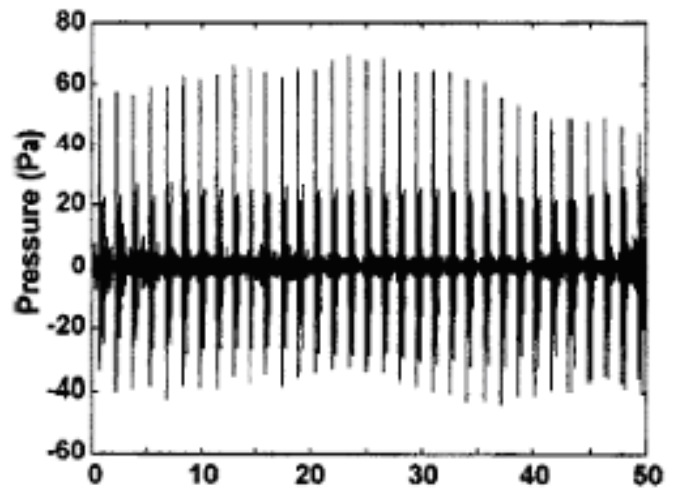

(a) 50 s time-domain waveform measured at a $80 \mathrm{~m}$ distance to pile pipe

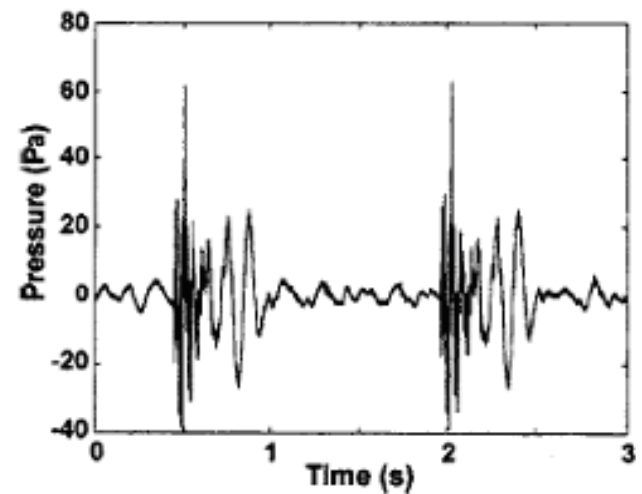

(b)Detailed observation between two pulses

Figure 3 the time waveform sequence of sound pressure in the underwater which recorded by $107 \mathrm{CM}$ pile pipe during the pilling process. 
Seen from Figure 4, at a distance of 60 moutside pile hole, peak sound pressure generated by pilling underwater no more than $160 \mathrm{Db}$, the sound pressure level of the peak SPL and average SPL are attenuated by the distance as shown in Figure 4.

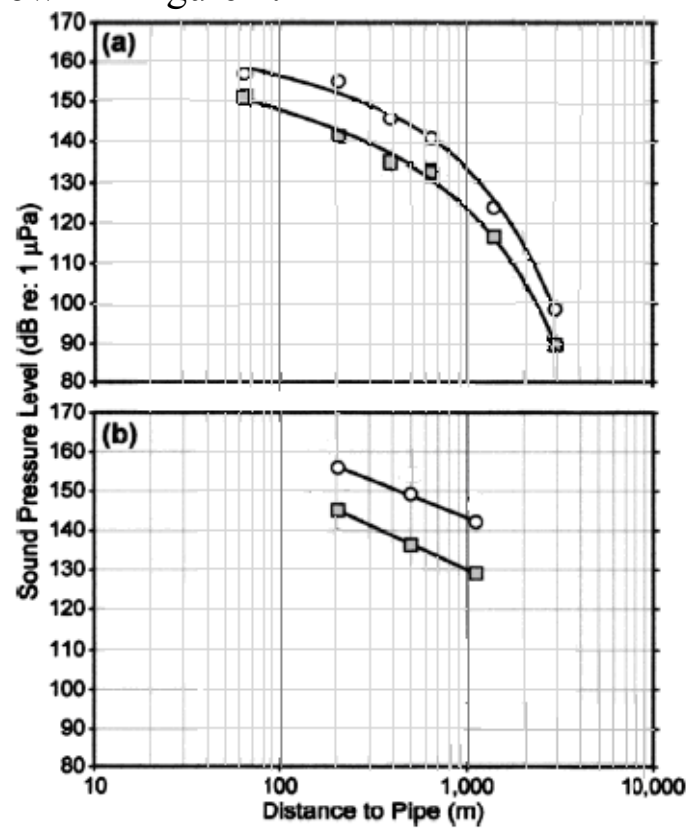

(a) $51 \mathrm{~cm}$ pile pipe $\quad$ (b) $107 \mathrm{~cm}$ pile tube

Figure 4. the curve change about peak SPL during the percussive piling process and average SPL

Table 1. Single pile of tumbling source scales $(10 \mathrm{~m})$ of the typical core material with different diameters pile, double value on behalf of the range

\begin{tabular}{lll}
\hline Pile(Diameter) & Peak Sound Pressure & Rms Sound Pressure \\
\hline Impact Concrete Pile $(61 \mathrm{~cm})$ & $183 / 193$ & $171 / 175$ \\
\hline Impact Steel Reinforced Pile $(30.5 \mathrm{~cm})$ & $190 / 200$ & $180 / 184$ \\
\hline Impact steel Pile $(70 \mathrm{~cm})$ & 206 & 188 \\
\hline Impact steel $(76 \mathrm{~cm})$ & 208 & 190 \\
\hline Impact steel $(244 \mathrm{~cm})($ distance $25 \mathrm{~m})$ & 212 & 197 \\
\hline
\end{tabular}

\section{UNDERWATER NOISE GENERATED BY FAN OPERATION CHANGED ACCORDING TO THE SPEED OF WIND}

\section{Fan noise in the air in different wind speeds}

Fan turbine sound power level relations with the wind speed, wind noise is enhanced with the increase of wind speed for each additional $1 \mathrm{~m} / \mathrm{s}$, the noise level increased by approximately $1 \mathrm{~dB}(\mathrm{~A}) /$ $20 \mu \mathrm{Pa}$.

Relationship between fan shaft rotational speed and the sound power level is $\mathrm{L} w$ the formula between the fan rotational speed $\mathrm{N}$ and the sound power level $\mathrm{L} w$ fitting is as follows:

$\mathrm{L} w=67.1 \log (\mathrm{N})+15.4 \mathrm{~dB}(\mathrm{~A})$

When the turbine rated wind speed of $12 \mathrm{~m} / \mathrm{s}$, the highest blade speed of about 18rpm, and the fan noise source intensity (mainly aerodynamic noise) is also the highest. When the wind speed is further increased fan noise and will not be further enhanced.

\section{Underwater noise of fan under different wind speeds}

Figure 5 is a German [Klaus Betke et al., 2004] study on the different fans, the noise spectrum level corresponding to different wind speeds;

Figure 6 is a Danish (Jakob Tougaard et al., 2009) study on noise spectrum offshore wind farm grade distribution in two different wind speeds. Danish Middelgrunden offshore wind farm, turbine type 2MW(In figure, gray for ocean background noise, blue for the fan noise; red(square) for harbor 
seals in the hearing threshold curve on this band; red)dot)dolphins and mouse hearing threshold curve on the band.

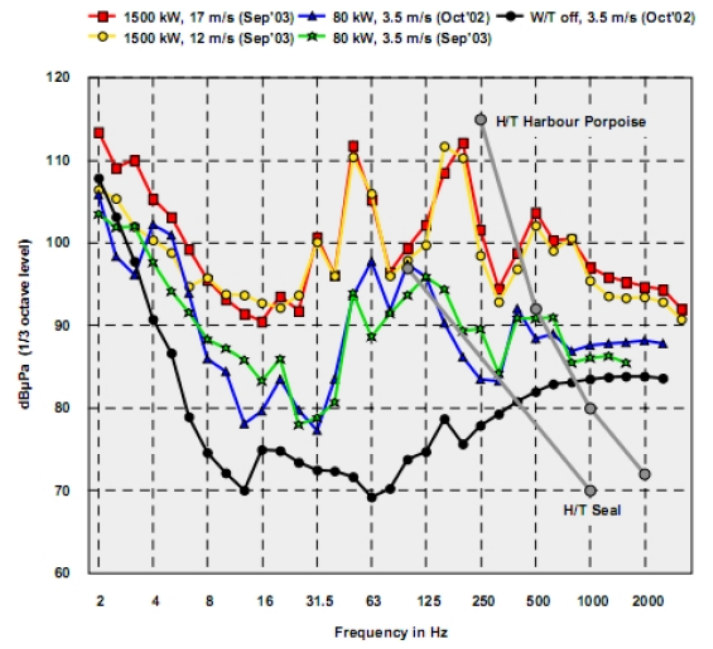

Figure 5 Underwater noises under different wind turbine of different fan
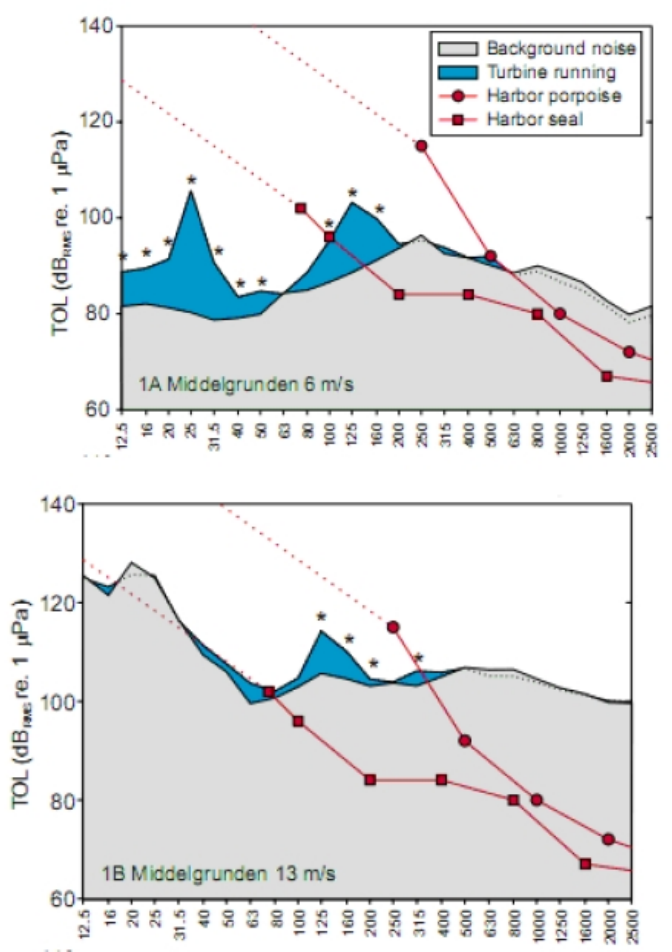

Figure 6 a wind farm in Denmark has different spectrum level under two different wind speeds

Different wind speeds, the fan noise intensity generated underwater obvious. Compared with the marine background noise, noise intensity different caused wind speeds different. Wind speed respectively $6 \mathrm{~m} / \mathrm{s}$ and $13 \mathrm{~m} / \mathrm{s}$ in different underwater radiation of fan(submerged in the background noise), When at low frequencies $(63 \mathrm{~Hz}$ or less) and high wind speed $(13 \mathrm{~m} / \mathrm{s})$, the fan noise is quite as the marine background like no change. High wind speed $(13 \mathrm{~m} / \mathrm{s})$ at the $125 \mathrm{~Hz}$ frequency reflection of fan is then the low wind speed $(6 \mathrm{~m} / \mathrm{s})$ wind turbines around underwater radiated noise spectrum level high $10 \mathrm{~dB} / 1 \mu \mathrm{Pa}$, but overall not high, and considerably as ocean background noise.

\section{IMPACT ON MARINE LIFE}

Affect the construction of offshore wind farms on marine life just a few months time, and in the decades-long operational period, the impact of wind turbine noise on marine life will be long-term and cumulative. Currently, marine biological research focused on the study of wind turbine noise on marine fish and marine mammals: including marine fish on the fan noise detection range is deter- 
mined, the noise cause behavioral and physiological responses in fish and the like; for marine mammals the study of animal behavior in mammals is mainly caused by noise fan running reactions, such as escape the noise source, increase the frequency of echolocation. Most studies show that the fan noise of marine fish and mammals may have some impact, but it will not cause adverse physiological reactions and hearing damage; the same time, some studies show that marine organisms can adapt well to the fan noise, does not adversely affect. Comparing the noise impact studies on marine benthos is less, and it would not affect the existence remains controversial.

Offshore wind farm monitoring results show that: Spectrum fan running in the underwater noise level substantially are more similar to the overall strength significantly smaller with increasing frequency, in $1 \sim 20 \mathrm{kHz}$ frequency distribution of the power spectrum level $140 \mathrm{~dB} / 1 \mu \mathrm{Pa}$ to $65 \mathrm{~dB} /$ between $1 \mu \mathrm{Pa}$, at $120 \mathrm{~Hz}$ to $1.5 \mathrm{kHz}$ with a wide spectrum of crony shape, strength increased to $10 \sim$ $20 \mathrm{~dB} / 1 \mu \mathrm{Pa}$. In the fan from the fan on the $3 \mathrm{rd} 200 \mathrm{~m}$ near bridges and waterways, the power spectrum $100 \mathrm{~Hz}$ point level reaches a maximum of $128 \mathrm{~dB} / 1 \mu \mathrm{Pa}$, than the same depth from the different power spectra increase $10 \sim 20 \mathrm{~dB} / 1 \mu \mathrm{Pa}$. Because underwater noise time - space - frequency characteristics change over time, measuring the vessel away from the wind farm is also measured at nearly $4 \mathrm{~km}$ crony-like low-frequency background noise distribution, so the overall intensity due to the noise caused by the fan is not, basically the waters other point measured the background noise similar. Survey found Shanghai East Sea Bridge in the operation when the vehicle more time (30 per minute), a significant impact on the underwater noise, mainly affecting low frequency below $100 \mathrm{~Hz}$, the rate of increase up to $10 \sim 20 \mathrm{~dB} / 1 \mu \mathrm{Pa}$.

\section{CONCLUSIONS}

Offshore wind farm monitoring results show that: Spectrum fan running in the underwater noise level substantially are more similar to the overall strength significantly smaller with increasing frequency, in $1 \sim 20 \mathrm{kHz}$ frequency distribution of the power spectrum level $140 \mathrm{~dB} / 1 \mu \mathrm{Pa}$ to $65 \mathrm{~dB} / 1 \mu \mathrm{Pa}$, at $120 \mathrm{~Hz}$ to $1.5 \mathrm{kHz}$ with a wide spectrum of crony shape, strength increased to $10 \sim 20 \mathrm{~dB} / 1 \mu \mathrm{Pa}$. Studies show that the fan noise of marine fish and mammals may have some impact, but it will not cause adverse physiological reactions and hearing damage; the same time, some studies show that marine organisms can adapt well to the fan noise, does not adversely affect.

\section{REFERENCES}

[1] R.J. Schusterman \& S.M.Van.Parijs,2003. Pinniped vocal communication: An introduction. Aquatic Mammals 29:177-180.

[2] Carder,D.A., Penner,R.H. \& Scronce, B.L. 1985, Demonstration of adaptation in beluga whale echolocation signals. J. Acoust. Soc. Am. 77:726-730.

[3] Jacobs, D. W., 1972,Auditory Frequency Discrimination in the Atlantic Bottlenose Dolphin (Tursiops truncates) Montagu: A Preliminary Report,Acoust. Soc. Am. 53: 696-698.

[4] Herman, L. M. \& Arbeit, W. R. 1972,Frequency Difference Limens in the Bottlenose Dolphin: 1-70 kHz, Aud. Res. 12, 109-120.

[5] Thompson, R. K. R. \& Herman, L. M., 1975, Underwater Frequency Discrimination in the Bottlenose Dolphin (1-140 kHz) and the Human (1-8 kHz), Acoust. Soc. Am. 57: 943-948.

[6] Charles R. Greene, Jr.,1987, Characteristics of oil industry dredge and drilling sounds in the Beaufort Sea[J]. J. Acoust. Soc. Am., 82(4): 1315-1324.

[7] John D. Hall \& Jon Francine, 1991,Measurements of underwater sounds from a concrete island drilling structure located in the Alaskan sector of the Beaufort Sea,Acoust. Soc. Am., 90(3): 16651667.

[8] Susanna B. Blackwell, 2004,Drilling and operational sounds from an oil production island in the ice-covered Beaufort Sea, Acoust. Soc. Am., 116(5): 3199-3211.

[9] G.P. van den berg. 2004,Effects of the wind profile at night on wind turbine sound,Journal of Sound and Vibration, 277:955 970. 
[10] Jakob Tougaard, 2009, Oluf Damsgaard Henriksen, Underwater noise from three types of offshore wind turbines: Estimation of impact zones for harbor porpoises and harbor seals, Acoust. Soc. Am. 125(6), :3766 3773.

[11] Songhai Li1,, 2012, Evoked-potential audiogram of an Indo-Pacific humpback dolphin (Sousa chinensis) ,The Journal of Experimental Biology 215, 3055-3063. 